\title{
Comparison of Two Solar-Assisted Underfloor Heating Systems with Phase Change Materials
}

\author{
Maria T. Plytaria ${ }^{1}$, Christos Tzivanidis ${ }^{1}$, Ioannis Alexopoulos ${ }^{1 *}$, Evangelos Bellos ${ }^{1}$, Kimon A. \\ Antonopoulos ${ }^{1}$ \\ ${ }^{I}$ Thermal Department, School of Mechanical Engineering, National Technical University of Athens, Greece, \\ E-mail: alexopoulosio@central.ntua.gr
}

Received 11 December 2018, Revised 05 May 2019, Accepted 12 August 2019

\begin{abstract}
:
In this work, two underfloor solar assisted heating systems without and with phase change materials (PCMs) are investigated energetically for a building of $100 \mathrm{~m}^{2}$ floor area, which is situated in Athens, (Greece). The simulations are conducted with the commercial software TRNSYS 17. More analytically, flat plate collectors coupled to a storage tank are used while there is, in the first system, an auxiliary heater and in the second system, a heat pump, for supplying the extra heating demand when the solar potential is not sufficient. The PCM layer (BioPCM Q29/M91) is situated below the underfloor heating system, which operates with water, in order to increase the storage capacity. Moreover, this study compares the indoor temperature profiles of the building with and without a PCM layer on the floor and specifically in different cases by changing the area of the collectors and the thickness of the insulation layer. The results showed that the electrical energy consumption decreases on average $70 \%$ and $41 \%$ for the system with an auxiliary heater and for the system with heat pump respectively. Moreover, the application of the PCM layer on the floor in both systems gives an increase of the indoor temperature about $2^{\circ} \mathrm{C}$ into the limits of thermal comfort.
\end{abstract}

Keywords: Underfloor heating system; auxiliary heater; heat pump; heating loads; phase change materials; TRNSYS.

\section{Introduction}

The increasing rate of the buildings' energy consumption is a problem that concerns many countries in the world. Solar energy can cover a considerable part of the energy demands of buildings [1-2]. It is important to state that a typical building can have a specific heating consumption up to $100 \mathrm{kWh} / \mathrm{m}^{2}$ year [3]. Athens has a solar radiation of about $1600 \mathrm{kWh} / \mathrm{m}^{2}$ year and this value makes it favorable for solar energy applications [4].

The energy systems, which are used in buildings for heating and cooling requirements, should integrate renewable systems in order to improve their energy performances and to be more environmentally friendly [5]. In literature, there are many investigations of systems, which reduce energy consumption. Dietrich et al. [6] studied the exergoeconomic performance of a pumped heat electricity storage system and they concluded that this system can be considered as a worthy solution for the storage of the electrical energy. Yokoyama et al. [7] proposed a method in order to investigate the energy performance of a $\mathrm{CO}_{2}$ heat pump water heating system. Castaing-Lasvignottes et al. [8] investigated a model of a compressed air energy storage system which was connected to photovoltaics panels and to the grid and their purpose was to eliminate the energy from the grid. Korkmaz and Eğrican [9] developed a model of solarassisted radiant heating and cooling systems of buildings in Istanbul and also, they studied their energy performance. They found that the combination of the floor heating and the chilled ceiling gave acceptable indoor conditions.
An underfloor heating system is an advantageous form for the buildings' heating [10]. It is also important to state that an underfloor heating system can reduce the heating loads by about $18 \%$ [11] and can ameliorate the indoor thermal conditions of the buildings [12]. In addition, the application of PCMs into the building envelope is another method, which improves the energy performance of buildings. PCMs can be added in windows [13], walls [14], roofs [15] and floors [16]. Ibrahim et al. [17] reviewed a considerable amount of literature relating to the heat transfer enhancement of PCMs for thermal energy storage applications. Moreover, Safari et al. [18] reviewed the supercooling of PCMs in thermal energy storage systems and they discussed applications with solar thermal storage.

The combination of solar-assisted underfloor heating systems and PCM layer is the objective of this study. PCM layer is used in order to increase the storage capacity and to decrease the energy demand. In literature, there are some investigations dealing with the application of PCM in radiant floor systems. For example, Lin et al. [19] carried out an experimental study of an underfloor electric system with PCM plates and they found that the use of PCM reduced the need for electricity. Ansuini et al. [20] developed a radiant floor system with the application of the PCM layer into it. Mazo et al. [21] investigated a model to simulate a floor heating system with PCM. In this study, a heat pump feeds the heating system in order to be a reduction of the electric energy consumption. Royon et al. [22] constructed and investigated a floor panel with PCM. 
Cheng et al. [23] carried out experiments and they found that the application of shape-stabilized PCM in the underfloor heating system can reduce the energy demand of a building. Devaux and Farid [24] concluded that the thermal comfort in a building is achieved when the melting point of the PCM, which is situated in the ceiling and in walls, is low and when the melting point of the PCM, which is situated in the floor with a heating system, is high. Mays et al. [25] studied an insulated building with an underfloor electric heating system with PCM and they found that the PCM creates a 6-hour shift in electricity consumption. Lu et al. [26] developed a model which consist of a PCM double tube floor and a solar water heating system. They concluded that the energy consumption can be reduced by about $6 \%$ with the use of PCM if the indoor temperature remains at $20^{\circ} \mathrm{C}$.

In the present study, two underfloor solar assisted heating systems without and with PCM layer are investigated energetically for a typical building of $100 \mathrm{~m}^{2}$ floor area. The simulations are conducted with the commercial software TRNSYS 17. Specifically, flat plate collectors coupled to a storage tank are used while there is, in the first system, an auxiliary heater and in the second system, a heat pump, for supplying the extra heating demand when the solar potential is not sufficient. The innovation of this study is the combination of a solar assisted heat pump with the incorporation of PCM in the underfloor heating system and the comparison of it with a system with an auxiliary heater. The PCM layer is situated below the underfloor heating system because in this way it can retain more heat by taking advantage of the heat capacity of the floor. It is important to state that the building is simulated with Type 56 [27] of TRNSYS and the PCM layer is simulated with Type 1270 from Thermal Energy System Specialists (TESS) Company [28].

\section{Material and Methods}

\subsection{The Examined Building}

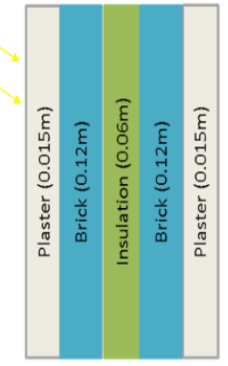

(a)

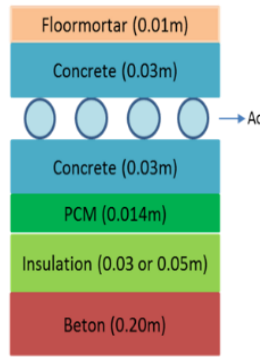

(b)

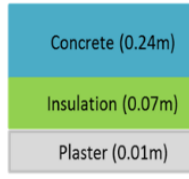

(c)
Figure 1: Structure of (a) the walls, (b) the floor, (c) the roof.
The examined building is an office of $100 \mathrm{~m}^{2}$ floor area in Athens. Its parameters have typical values which are given analytically in Table 1. Moreover, Figure 1 depicts the structure of the walls, floor and roof. Moreover, an "active layer" is added to the floor in order to model an underfloor heating system. This "active layer" contains fluid-filled pipes (Figure 2) that either add or remove heat from the surface. Furthermore, the desired inlet mass flow rate in the pipes is given by the program and determines the segmentation of the area for the underfloor system. In our case, the specific mass flow rate of $8 \mathrm{~kg} / \mathrm{hm}^{2}$ separates the area into four segments. It is important to state that by changing the area segmentation, the system operation is improved.

The desired temperatures were set to be $21^{\circ} \mathrm{C}-22^{\circ} \mathrm{C}$ in winter. The minimum theoretical heating energy to cover this thermal comfort condition is about $2500 \mathrm{kWh}$, or 25 $\mathrm{kWh} / \mathrm{m}^{2}$, which was calculated by TRNSYS. For the incorporation of the PCM layer on the floor was used Type 1270 , which is a component of TRNSYS from Thermal Energy System Specialists (TESS) Company and in Table 2 are given its physical properties. Figure 3 shows the DSC and the enthalpy curves of PCM. The position of the PCM layer is visible in figure $1 \mathrm{~b}$. Type 1270 has built-in values for a specific brand of PCM, the BioPCM. BioPCM is a commercial grade macro encapsulated $\mathrm{PCM}$ available in a mat form, in which refined fatty acids are filled in square pouches. The selected PCM has the product name code M91 and it is offered in four different melting temperatures namely $23,25,27$ and $29^{\circ} \mathrm{C}$. Since the PCM will be used with an underfloor heating system (with hot water) in a building, which operates close to $40^{\circ} \mathrm{C}$, a reasonable melting temperature is $29^{\circ} \mathrm{C}$, which is the highest of the selected temperatures and closest to the hot water temperatures. So, in this work, the BioPCM Q29/M91 has been selected.

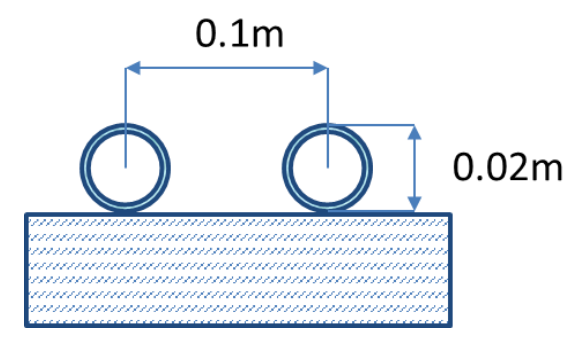

Figure 2: Parameters of pipes of the active layer.

Table 1. Building's Parameters [27].

\begin{tabular}{ll|ll}
\hline Parameter & Value & Parameter & Value \\
\hline Floor area & $100 \mathrm{~m}^{2}$ & Specific Gains (equipment) & $350 \mathrm{~W}$ \\
Height of the building & $3 \mathrm{~m}$ & Persons in the building & 7 \\
South double window & $6 \mathrm{~m}^{2}$ & Light power & $500 \mathrm{~W}$ \\
East double window & $3 \mathrm{~m}^{2}$ & Shading coefficient & $60 \%$ \\
West double window & $3 \mathrm{~m}^{2}$ & Window U-value & $1.4 \mathrm{~W} / \mathrm{m}^{2} \mathrm{~K}$ \\
Wall U-value & $0.51 \mathrm{~W} / \mathrm{m}^{2} \mathrm{~K}$ & Roof U-Value & $0.467 \mathrm{~W} / \mathrm{m}^{2} \mathrm{~K}$ \\
Orientation of building & South & Floor U-Value & $0.648 \mathrm{~W} / \mathrm{m}^{2} \mathrm{~K}$ \\
Air changes per hour & $0.8 \mathrm{ach}$ & Building operation hours & $6: 00 \mathrm{am}-18: 00 \mathrm{pm}$ \\
\hline
\end{tabular}


Table 2. Physical Properties of PCM, which is Used in Simulations [29].

\begin{tabular}{ll}
\hline Product BioPCM & Q29/M91 \\
\hline Weight per area $\left(\mathrm{kg} / \mathrm{m}^{2}\right)$ & 6.15 \\
Thickness $(\mathrm{mm})$ & 14 \\
Dimensions/width $(\mathrm{mm})$ & 419.1 \\
Melting temperature $\left({ }^{\circ} \mathrm{C}\right)$ & 29 \\
Freezing temperature $\left({ }^{\circ} \mathrm{C}\right)$ & 23.5 \\
Density (liquid) $\left(\mathrm{kg} / \mathrm{m}^{3}\right)$ & 850 \\
Density (solid) $\left(\mathrm{kg} / \mathrm{m}^{3}\right)$ & 1400 \\
Thermal conductivity $($ liquid $)(\mathrm{W} / \mathrm{mK})$ & 0.15 \\
Thermal conductivity (solid) $(\mathrm{W} / \mathrm{mK})$ & 2.5 \\
Specific heat capacity (liquid) $(\mathrm{J} / \mathrm{kgK})$ & 2200 \\
Specific heat capacity (solid) $(\mathrm{J} / \mathrm{kgK})$ & 4500 \\
Latent heat storage capacity $(\mathrm{kJ} / \mathrm{kg})$ & 210 \\
\hline
\end{tabular}

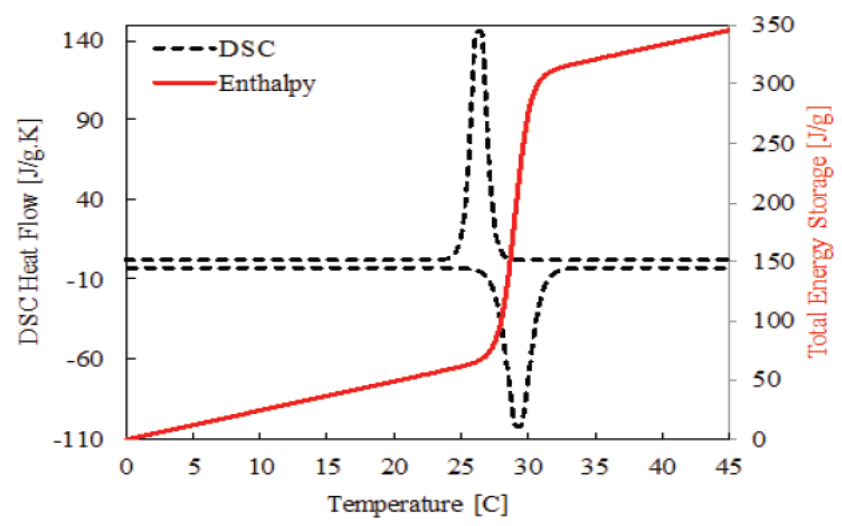

Figure 3. DSC and enthalpy curves of BioPCM (Q29/M91) [29].

\subsection{Basic Mathematical Formulation}

The useful collector energy and the collector efficiency are given by the following equations:

$Q_{u}=\dot{m}_{c} \cdot C_{P} \cdot\left(T_{f, o}-T_{f, i}\right)$

$Q_{s}=A_{c} \cdot G_{T}$

The basic equation which gives the energy balance in the storage tank is:

$Q_{\text {source }}=Q_{\text {st }}+Q_{\text {load }}+Q_{\text {loss }}$

where the source is the energy from the collectors, the load is the heat which enters the building and loss is the radiant losses to the environment.

\section{Auxiliary Heater}

The heater adds heat to the flow stream at a rate less than or equal to $\mathrm{Q}_{\text {aux,max }}$, which is a user-determined quantity, whenever the control function is equal to one and the outlet temperature is less than the set-point $\mathrm{T}_{\text {set }}$, which is set to be $45^{\circ} \mathrm{C}$. The operation of the auxiliary heater is described from the following equations:

$$
\begin{aligned}
& Q_{\text {aux }} \leq Q_{\text {aux }, \text { max }} \\
& Q_{\text {aux }}=\min \left(Q_{\text {auux }, \max }, m_{h s} \cdot C_{p} \cdot\left(T_{\text {set }}-T_{l}\right)\right)
\end{aligned}
$$

The auxiliary heating is provided by an electrical resistance of $3 \mathrm{~kW}$. This value is selected after a simple sensitivity analysis in order to have an acceptant indoor temperature profile and to achieve a relatively low electricity consumption. So, the symbol $\left(P_{e l}\right)$ is also used instead of $\left(Q_{\text {aux }}\right)$. The heating load of the building can be calculated as:
$Q_{h}=m_{h s} \cdot C_{p} \cdot\left(T_{\text {in }}^{B}-T_{\text {out }}^{B}\right)$

where $C_{p}$ is the specific heat capacity of water and it is equal to $4.19 \mathrm{~kJ} / \mathrm{kg} \mathrm{K}$

The solar coverage for both systems can be calculated by taking into account the energy that consumed from it $\left(\mathrm{P}_{\mathrm{el}}\right)$, according to the following equation:

$f=1-\frac{P_{e l}}{Q_{h}}$

Type 1270 (PCM layer)

According to TESSLibs3-Mathematical Reference [28], Type1270 is mathematically quite simplistic. The freeze/thaw process of PCM material occurs at a constant temperature and its specific heat is constant in the solid phase and in the liquid phase.

More analytically, when the PCM material is fully frozen, the final temperature is equal to:

$$
T_{\text {final }}=T_{\text {initial }}+\frac{\left(\dot{q}_{1}+\dot{q}_{2}\right)}{m_{P C M} \cdot C_{p, \text { solid }}}
$$

When the PCM material is fully thawed, the final temperature is equal to:

$T_{\text {final }}=T_{\text {initial }}+\frac{\left(\dot{q}_{1}+\dot{q}_{2}\right)}{m_{P C M} \cdot C_{p, \text { liquid }}}$

where $q_{1}$ and $q_{2}$ are the quantities of energy entering the PCM from the adjacent wall layers, $m_{P C M}$ is the mass of the PCM, $C_{p, \text { solid }}$ is the specific heat capacity at the solid 
state of PCM and $C_{p \text {,liquid }}$ is the specific heat capacity at the liquid state of PCM. The initial and final temperature of the PCM material are equal when it is in a transition phase and Type1270 simply keeps track of how much energy the PCM has absorbed or given off. If the energy absorbed by the PCM during a particular time step exceeds the PCM's latent storage capacity then Type 1270 computes how much of the energy was needed to fully melt the PCM, then applies the remaining energy to a temperature change in the liquid phase using (9). Likewise, if the PCM is giving off energy to the surrounding wall layers and gives off more energy than the stored amount in a particular time step, then Type 1270 computes how much energy was required to fully solidify the PCM and applies the remaining energy to a temperature change in the solid phase using (8) [28].

\subsection{Description of the examined systems}

In this work, the simulation tool is TRNSYS 17 and the calculations are carried out when there is a heating demand in Athens, thus from November to April. Two different solar-assisted underfloor heating systems with and without a PCM layer on the floor are presented and compared energetically. In all cases, the storage tank volume is selected $1 \mathrm{~m}^{3}$. Table 3 gives the values of the parameters of the system.

The first system is a solar-assisted underfloor heating system with an auxiliary heater (Figure 4). More analytically, flat plate collectors heat water which is stored in the tank. After the storage tank, there is an auxiliary heater which is activated when the solar energy is not enough. The water of the auxiliary heater flows inside the tubes under the floor of the building when the indoor temperature of the building is low. Then, this water returns to the storage tank. It is important to state that the temperature of this water has to be lower than $45^{\circ} \mathrm{C}$ for the tubes' protection. So, when the temperature of the water exceeds this limit, there is a mixing of the water, which goes to the building, with the water which returns from it. The auxiliary heater operates fewer hours due to the incorporation of the PCM layer on the floor which increases the storage capacity. The desired inside temperature was selected at $22^{\circ} \mathrm{C}$ and the auxiliary heater operates when the inside temperature is lower than $21^{\circ} \mathrm{C}$ in order to decrease the auxiliary energy. A parametric analysis of this system is made in order to optimize it achieving the lowest energy consumption and the greatest solar coverage. The main parameters that influence the system performance are the collecting area of FPC and the thickness of the insulation of the floor. Table 3 gives the values of the system parameters.

The second system is the same as the first one but instead of the auxiliary heater, there is a water-to-water heat pump (Figure 5). The heat pump operates fewer hours due to the incorporation of the PCM layer on the floor, which increases the storage capacity.

Table 3. Values of the System Parameters.

\begin{tabular}{ll|ll}
\hline Parameters & Values & Parameters & Values \\
\hline Collecting area & $10-25 \mathrm{~m}^{2}$ & Tank volume & $1 \mathrm{~m}^{3}$ \\
Collector optical efficiency & $75 \%$ & Auxiliary heater power & $3 \mathrm{~kW}$ \\
Slope angle of the collector & $45^{\circ}$ & Heater thermostat temperature & $21-22^{\circ} \mathrm{C}$ \\
Collector thermal loss coefficient & $4 \mathrm{~W} / \mathrm{m}^{2} \mathrm{~K}$ & Operation hours of collectors & $6: 00-18: 00$ \\
Collector water mass flow rate & $1500 \mathrm{~kg} / \mathrm{h}$ & Rated heating capacity per heat pump & $3 \mathrm{~kW}$ \\
Heating system water flow rate & $1500 \mathrm{~kg} / \mathrm{h}$ & Scale factor of heat pump & 1 \\
\hline
\end{tabular}

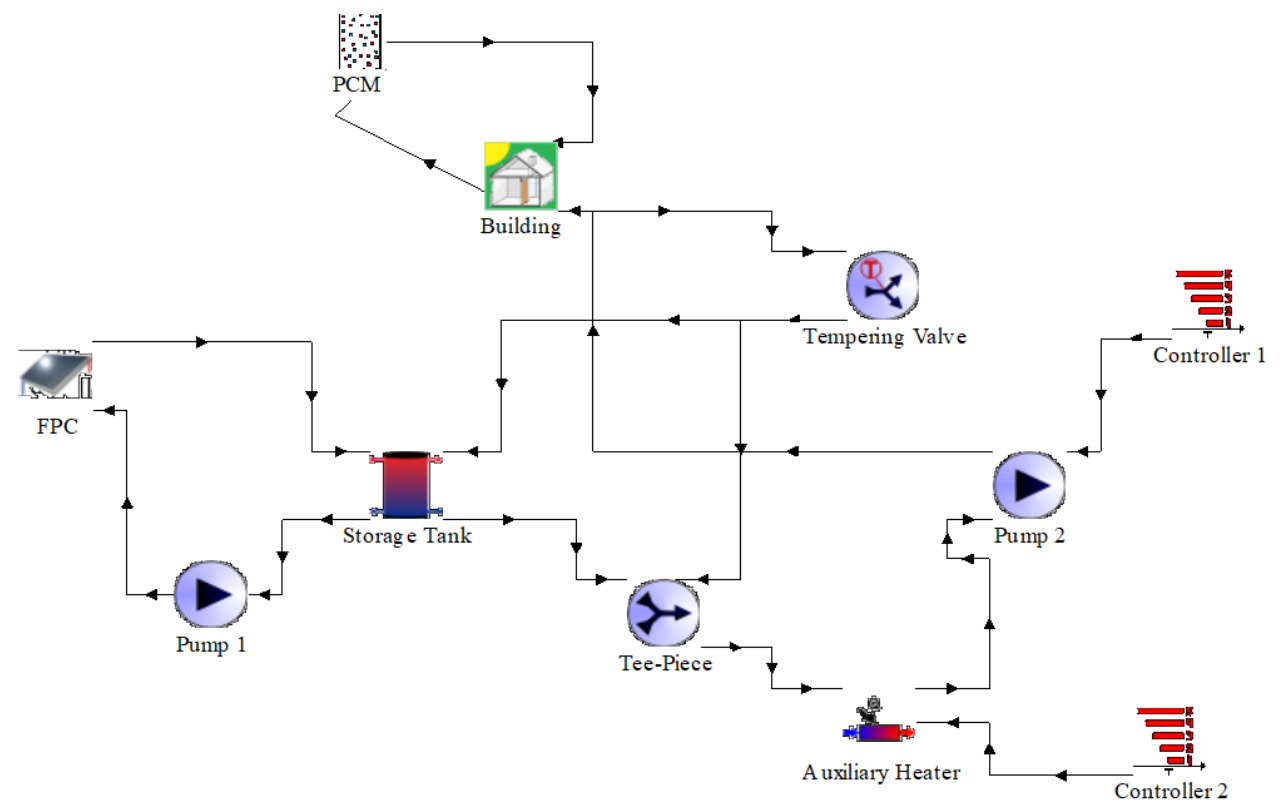

Figure 4. The examined system with the auxiliary heater. 


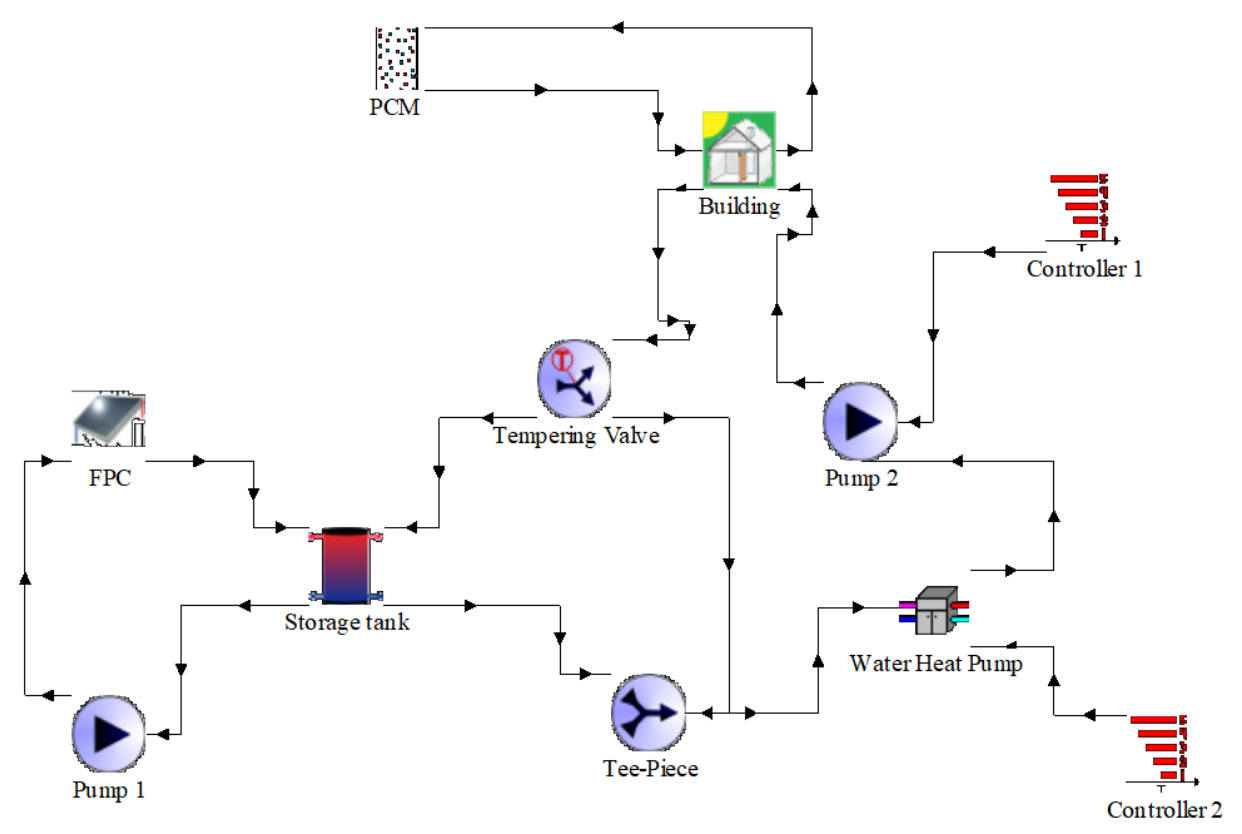

Figure 5. The examined system with heat pump.

\section{Results and discussion}

Figures 6a-b show the useful collector energy for various collecting areas for the two systems with auxiliary heater and with heat pump respectively. More analytically, for the system with an auxiliary heater (Figure 6a), there is a reduction of energy with the application of the PCM layer below the heating system ranging between $5 \%$ and $8.8 \%$. For the system with heat pump (Figure 6b), there is a decrease in energy with the application of the PCM layer below the heating system of about $1.5 \sim 2.0 \%$. It is important to state that the difference between the results in both systems in comparison with the insulation of $0.05 \mathrm{~m}$ and $0.03 \mathrm{~m}$ is imperceptible.
Figures $7 \mathrm{a}-\mathrm{b}$ show the electrical energy consumption for various collecting areas for both systems. For the system with an auxiliary heater (Figure 7a) there is a reduction of energy, on average $69.5 \%$, with the application of the PCM layer below the heating system. Furthermore, the change of the thickness of the insulation plays an insignificant role. For the system with heat pump (Figure $7 b$ ) there is a reduction of energy consumption, on average $41 \%$, with the PCM layer in the same place. Furthermore, the change of the thickness of the insulation doesn't seem to play an important role but the best case in both systems is when the insulation is $0.05 \mathrm{~m}$.

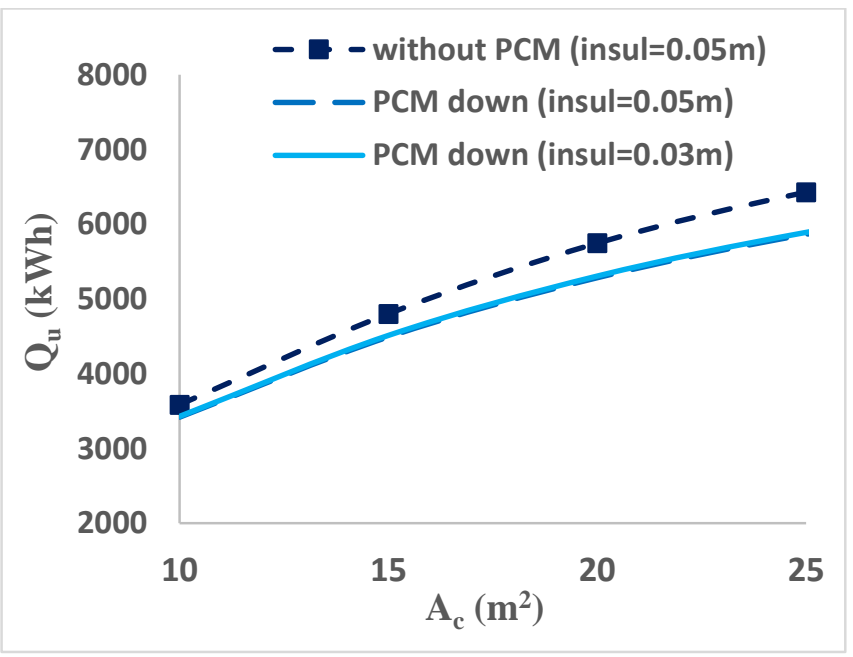

Figure 6a. The useful solar energy production for various collecting areas for the system with auxiliary heater.

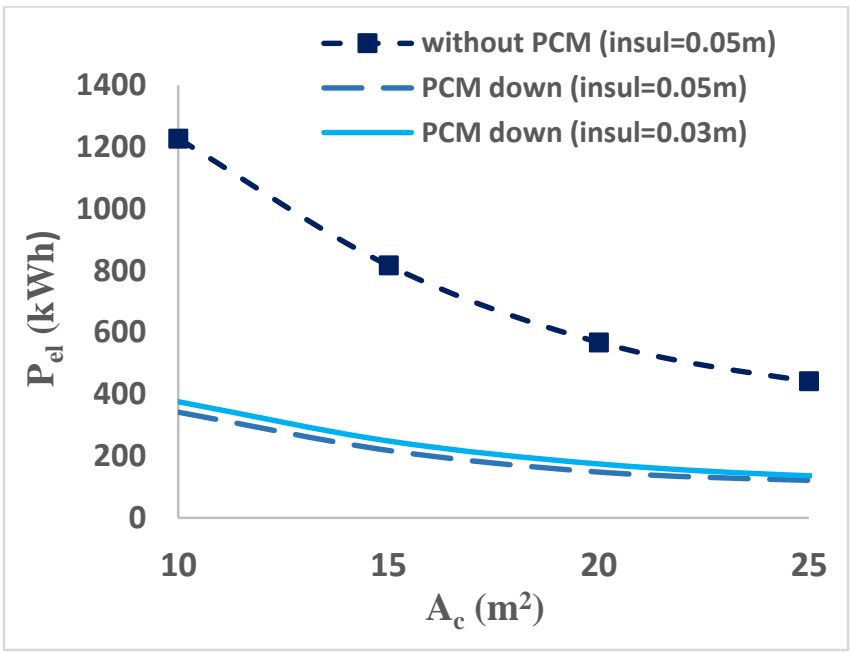

Figure 7a. The electricity consumption for various collecting areas for the system with auxiliary heater. 


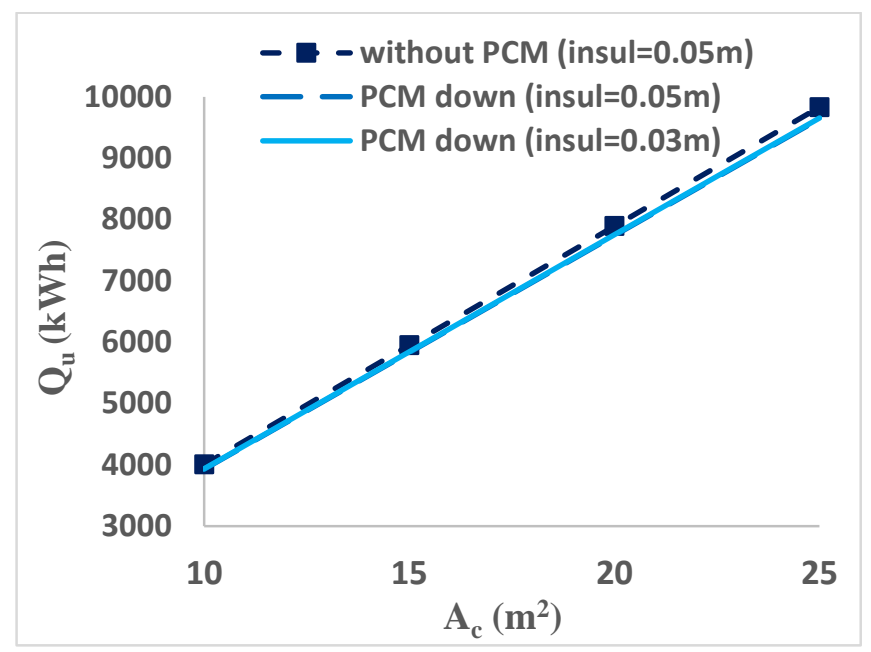

Figure 6b. The useful solar energy production for various collecting areas for the system with a heat pump.

Figure 8 illustrates a comparison of the electrical energy consumption of the two systems when there isn't a PCM layer and when there is a PCM layer below the heating system with the best case of the insulation $(0.05 \mathrm{~m})$. The higher reduction of the electrical energy consumption is after the collecting area $15 \mathrm{~m}^{2}$, with the use of PCM in a system with the auxiliary heater.

Figures 9a-b show the solar coverage for different collecting areas of the two systems. For the system with an auxiliary heater (figure 9a), there is an increase in the solar coverage for higher collecting areas and the maximum solar coverage is $90 \%$. Furthermore, the application of the

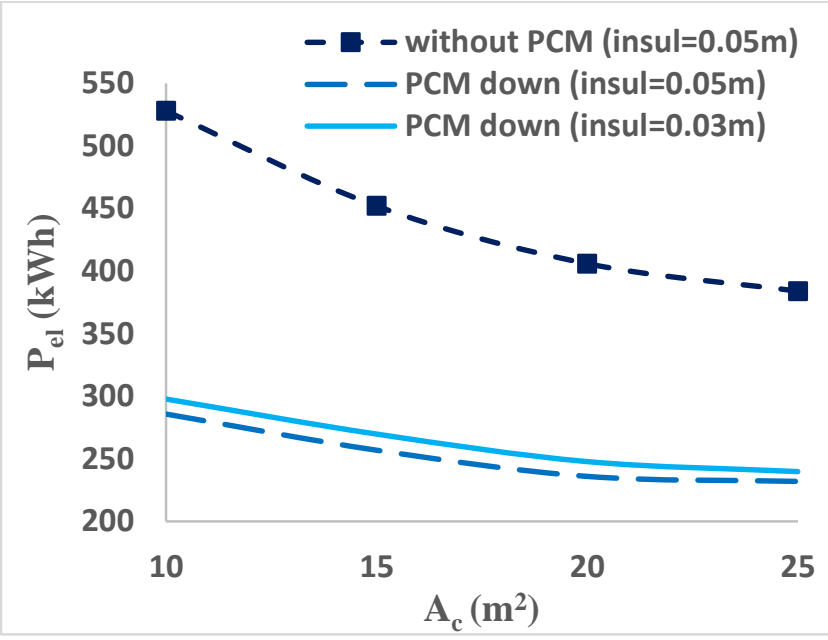

Figure $7 b$. The electricity consumption for various collecting areas for the system with a heat pump.

PCM layer below the underfloor heating system creates an increase of solar coverage ranging between $2.5 \%$ and $3.7 \%$ in comparison with the basic case without a PCM. The difference between the results in comparison with the insulation of $0.05 \mathrm{~m}$ and $0.03 \mathrm{~m}$ is imperceptible. For the system with heat pump (figure 9b), the maximum solar cover is about $84 \%$ and it is found for collecting areas about $20 \sim 25 \mathrm{~m}^{2}$. The solar coverage is higher for the PCM cases with a deviation of $0.5 \%$. This fact indicates that the use of PCM leads to more efficient operation of the heat pump.

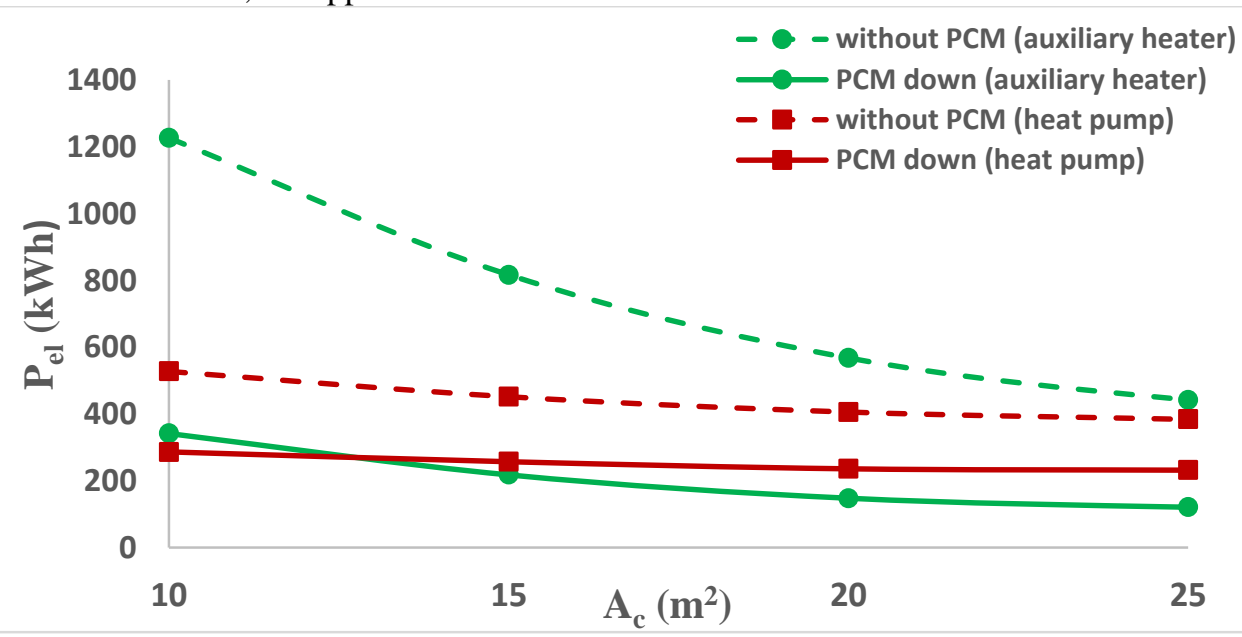

Figure 8. The electricity consumption for the system with the auxiliary heater and system with heat pump without and with PCM below the heating system. 


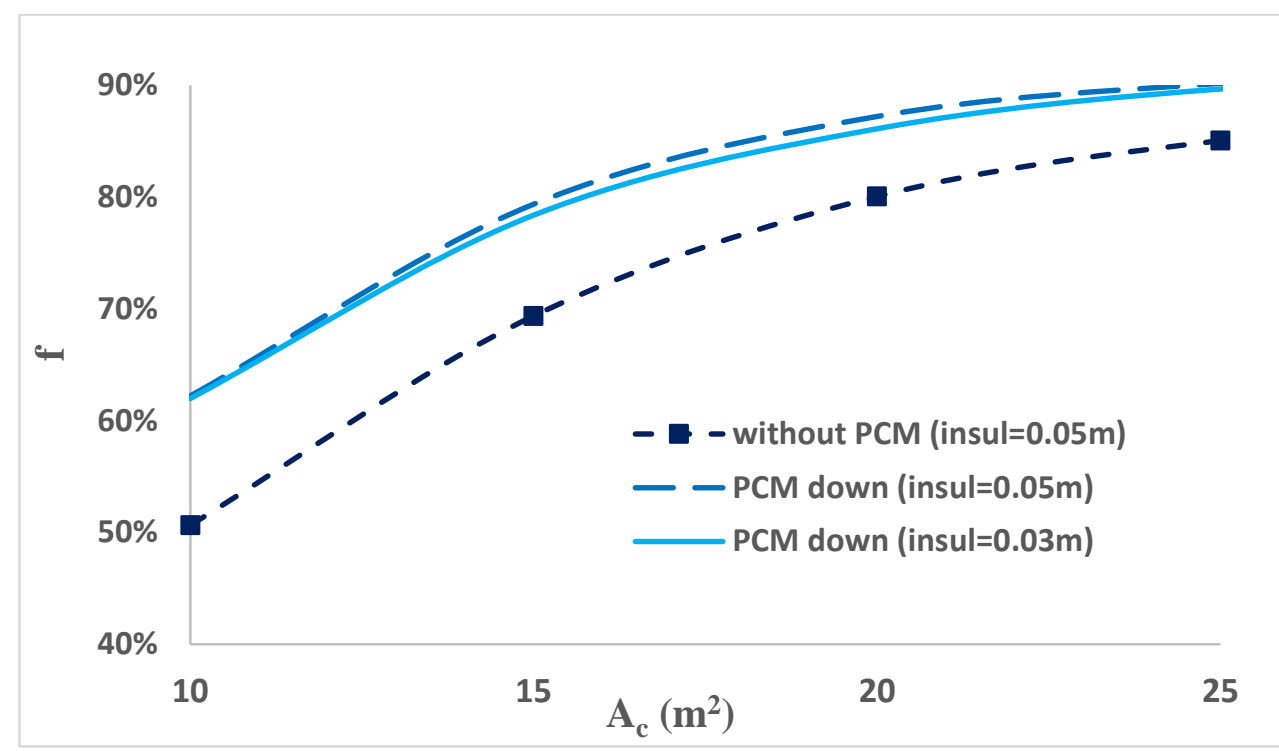

Figure $9 a$. The solar coverage for various collecting areas for the system with auxiliary heater.

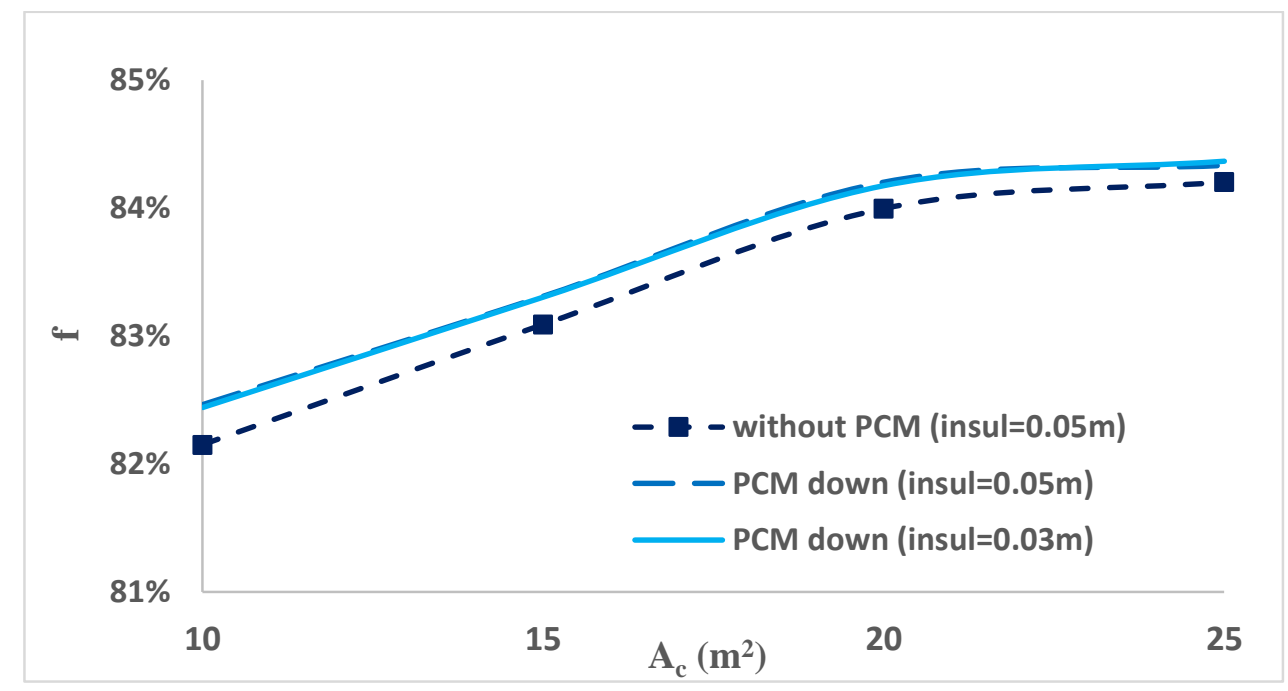

Figure 9b. The solar coverage for various collecting areas for the system with a heat pump.

Figure 10 shows the indoor temperature's fluctuation for the two examined systems without and with PCM layer below the heating system and the best case of the insulation $(0.05 \mathrm{~m})$ in winter period in Athens $\left(1^{\mathrm{st}}\right.$ November-15 $5^{\text {th }}$ April). It is clear that the temperature's fluctuations for all the examined cases are into the limits of thermal comfort and the cases with PCM give an increase of the temperature (over $21^{\circ} \mathrm{C}$ ) in comparison with the cases without PCM.

The results are clearest in Figure 11, which shows the temperature's fluctuation for the same cases but for the duration of two days ( $15^{\text {th }}$ November- $16^{\text {th }}$ November). It is obvious that with the application of PCM in both systems, there is an increase in the indoor temperature about $2^{\circ} \mathrm{C}$. PCM works by increasing the thermal mass of a building, which not only can reduce the heat transfer rate during peak periods, but can also reduce relatively large internal temperature fluctuations 


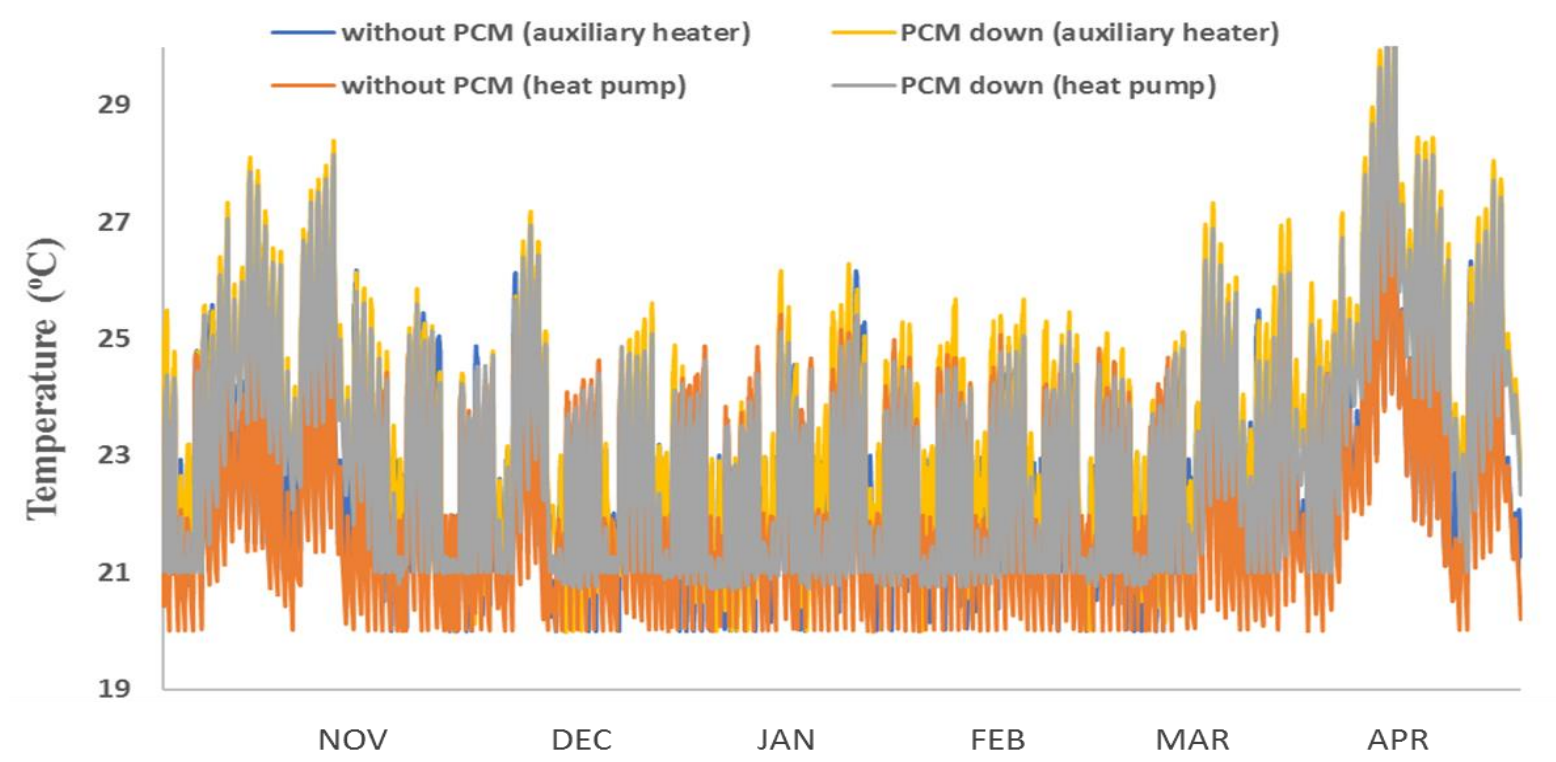

Figure 10. Temperature's fluctuation for different cases during the winter period in Athens.

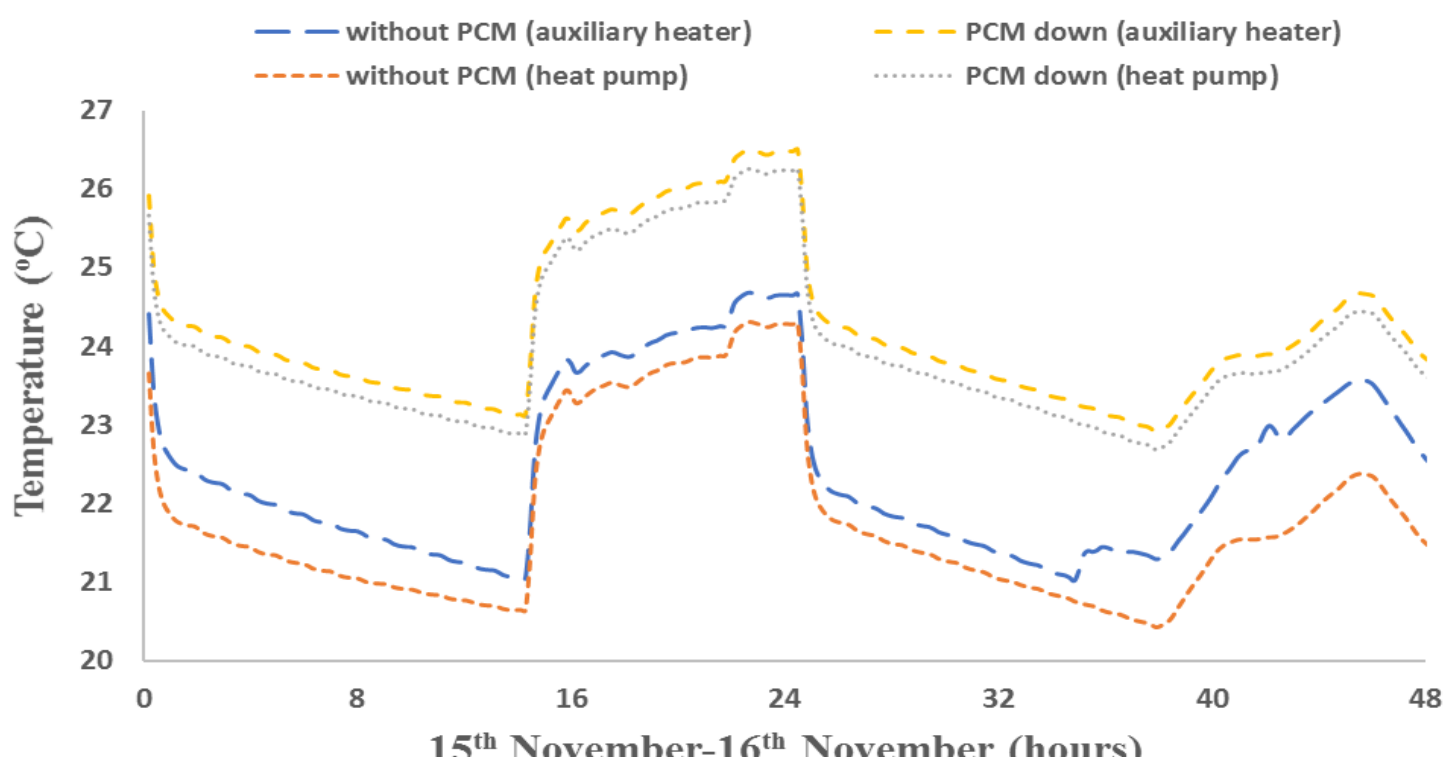

Figure 11. Temperature's fluctuation for different cases during $15^{\text {th }}-16^{\text {th }}$ November in Athens.

\section{Conclusions}

A comparison of two solar-assisted underfloor heating systems of a building in Athens with and without the application of a PCM layer below the heating system is presented and is theoretically evaluated. The main conclusions are given the following:

- The two examined solar-assisted underfloor heating systems can heat efficiently a building with a specific heating demand of $25 \mathrm{kWh} / \mathrm{m}^{2}$.

- The use of the PCM layer on the floor reduces the useful collector energy on average $7 \%$ in the system with the auxiliary heater and about $2 \%$ in the system with a heat pump.

- It is observed that for greater collecting area, there is lower energy consumption. Moreover, the electrical energy consumption decreases on average $69.5 \%$ for the system with auxiliary heater and on average $41 \%$ for the system with a heat pump with the application of PCM layer on the floor, below the heating system.

- The change of the thickness of the insulation plays a negligible role.
- The optimum value for the auxiliary heater power is 3 $\mathrm{kW}$, which is close to the maximum heating load of the building.

- The higher reduction of the electrical energy consumption is after the collecting area $15 \mathrm{~m}^{2}$, with the use of PCM in the system with an auxiliary heater.

- For greater collecting area, there is an increase in solar coverage.

- The application of the PCM layer on the floor in both systems gives an increase of the indoor temperature about $2^{\circ} \mathrm{C}$ into the limits of thermal comfort.

\section{Acknowledgments}

M. Plytaria would like to thank the Special Account Research Funds of the National Technical University of Athens for its financial support. Moreover, E. Bellos would like to thank "Bodossaki Foundation" for its financial support.

\section{Nomenclature}

$\begin{array}{ll}\mathrm{A}_{\mathrm{c}} & \text { collecting area, } \mathrm{m}^{2} \\ \mathrm{C}_{\mathrm{p}} & \text { specific heat capacity, } \mathrm{kJ} /(\mathrm{kg} \mathrm{K})\end{array}$ 
$\mathrm{C}_{\mathrm{p} \text {,liquid }}$ specific heat capacity at liquid state, $\mathrm{kJ} /(\mathrm{kg} \mathrm{K})$

$\mathrm{C}_{\mathrm{p} \text {,solid }}$ specific heat capacity at solid state, $\mathrm{kJ} /(\mathrm{kg} \mathrm{K})$

f solar cover, -

$\mathrm{G}_{\mathrm{t}} \quad$ solar irradiation on the titled surface, $\mathrm{W} / \mathrm{m}^{2}$

$\mathrm{k}$ thermal conductivity, $\mathrm{W} /(\mathrm{m} \mathrm{K})$

$\mathrm{m}$ mass flow rate, $\mathrm{kg} / \mathrm{s}$

$\mathrm{m}_{\mathrm{pcm}} \quad$ mass of the PCM, $\mathrm{kg}$

$\mathrm{Q}$ energy, $\mathrm{kWh}$

$\dot{q}_{1}, \dot{q}_{2} \quad$ energy quantities, $\mathrm{kJ}$

$\mathrm{T}$ temperature, ${ }^{\circ} \mathrm{C}$

$\mathrm{U}$ thermal transmittance, $\mathrm{W} /\left(\mathrm{m}^{2} \mathrm{~K}\right)$

$\mathrm{V} \quad$ storage tank volume, $\mathrm{m}^{3}$

\section{Subscripts and superscripts}

B building

c collector

$\mathrm{f}_{\text {,in }} \quad$ fluid inlet

$\mathrm{f}$, out fluid outlet

h heating

h,s heating system

in indoor

1 load

max maximum

min minimum

out outdoor

s solar

st storage

th thermal

\section{References}

[1] S. Li, J. Joe, J. Hu, P. Karava, "System identification and model-predictive control of office buildings with integrated photovoltaic-thermal collectors, radiant floor heating and active thermal storage," Solar Energy, 113, 139-157,2015.

[2] C. Tzivanidis, E. Bellos, G. Mitsopoulos, K. A. Antonopoulos, A. Delis, "Energetic and financial evaluation of solar assisted heat pump heating system with other usual heating systems in Athens," Applied Thermal Engineering, 106, 87-97,2016.

[3] D. A. Asimakopoulos, M. Santamouris, I. Farrou, M. Laskari, M. Saliari, G. Zanis, G. Giannakidis, K. Tigas, J. Kapsomenakis, C. Douvis, S. C. Zerefos, T. Antonakaki, C. Giannakopoulos, "Modelling the energy demand projection of the building sector in Greece in the 21st century," Energy and Buildings, 49, 488-498,2012.

[4] E. Bellos, C. Tzivanidis, "Alternative designs of parabolic trough solar collectors", Progress in Energy and Combustion Science, 71, 81-117,2019.

[5] D. Borello, S. Evangelisti, E. Tortora, "Modelling of a CHP SOFC system fed with biogas from anaerobic digestion of municipal waste integrated with solar collectors and storage unit," Int. J. of Thermo., 16, 2835,2013 .

[6] A. Dietrich, F. Dammel, P. Stephan, "Exergoeconomic analysis of a pumped heat electricity storage system with concrete thermal energy storage," Int. J. of Thermo., 19, 43-51,2016.
[7] R. Yokoyama, R. Kato, T. Wakui, K. Takemura, "Performance estimation and optimal operation of a $\mathrm{CO}_{2}$ heat pump water heating system," Int. J. of Thermo., 16, 62-72,2013.

[8] J. Castaing-Lasvignottes, M. David, S. Simpore, O. Marc, F. Garde, "Simulating a compressed air energy storage system for a net zero energy building in tropics," Int. J. of Thermo., 19, 130-135,2016.

[9] A. Korkmaz, N. Eğrican, "Solar assisted conditioning of residences with floor heating and ceiling cooling: review and simulation results," Int. J. of Thermo., 18, 235-244,2015.

[10] A. K. Athienitis, T. Y. Chen, "Experimental and theoretical investigation of floor heating with thermal storage," ASHRAE Transactions, 99,1049$1057,1993$.

[11] K. Ghali, "Economic viability of underfloor heating system: A case study in Beirut climate," in ICREPQ 2007: Proceedings of the International Conference on Renewable Energies \& Power Quality, Sevilla, Spain, pp. 140-144, 2007.

[12] C. Inard, A. Meslem, P. Depecker, "Energy consumption and thermal comfort in dwelling-cells: A zonal-model approach," Building and Environment, 33, 279-291,1998.

[13] S. Li, K. Zou, G. Sun, X. Zhang, "Simulation research on the dynamic thermal performance of a novel triple-glazed window filled with PCM," Sustainable Cities and Society, 40, 266-273,2018.

[14] J. Xie, W. Wang, P. Sang, J. Liu, "Experimental and numerical study of thermal performance of the PCM wall with solar radiation," Construction and Building Materials, 177, 443-456,2018.

[15] M. Saffari, C. Piselli, A. De Gracia, A. L. Pisello, F. Cotana, L. F. Cabeza, "Thermal stress reduction in cool roof membranes using phase change materials (PCM)," Energy and Buildings, 158, 1097-1105,2018.

[16] G. Feng, K. Huang, H. Xie, H. Li, X. Liu, S. Liu, C. Cao, "DSC test error of phase change material (PCM) and its influence on the simulation of the PCM floor," Renewable Energy, 87, 1148-1153,2016.

[17] N.I. Ibrahim, F.A. Al-Sulaiman, S. Rahman, B.S. Yilbas, A.Z. Sahin, "Heat transfer enhancement of phase change materials for thermal energy storage applications: a critical review," Renewable and Sustainable Energy Reviews, 74, 26-50,2017.

[18] A. Safari, R. Saidur, F.A. Sulaiman, Y. Xu, J. Dong, "A review on supercooling of phase change materials in thermal energy storage systems," Renewable and Sustainable Energy Reviews, 70, 905-919,2017.

[19] K. Lin, Y. Zhang, X. Xu, H. Di, R. Yang, P. Qin, "Experimental study of under-floor electric heating system with shape-stabilized PCM plates," Energy and Buildings, 37, 215-220,2005. 
[20] R. Ansuini, R. Larghetti, A. Giretti, M. Lemma, "Radiant floors integrated with PCM for indoor temperature control," Energy and Buildings, 43, 3019-3026,2011.

[21] J. Mazo, M. Delgado, J. M. Marin, B. Zalba, "Modeling a radiant floor system with phase change material (PCM) integrated into a building simulation tool: Analysis of a case study of a floor heating system coupled to a heat pump," Energy and Buildings, 47, 458-466,2012.

[22] L. Royon, L. Karim, A. Bontemps, "Optimization of PCM embedded in a floor panel developed for thermal management of the lightweight envelope of buildings," Energy and Buildings, 82,385-390,2014.

[23] W. Cheng, B. Xie, R. Zhang, Z. Xu, Y. Xia, "Effect of thermal conductivities of shape stabilized PCM on under-floor heating system," Applied Energy, 144, 10-18,2015.

[24] P. Devaux, M. M. Farid, "Benefits of PCM underfloor heating with PCM wallboards for space heating in winter," Applied Energy, 191, 593602,2017 .
[25] A. E. Mays, R. Ammar, M. Hawa, M. A. Akroush, F. Hachem, M. Khaled, M. Ramadan, "Using phase change material in under floor heating," Energy Procedia, 119, 806-811,2017.

[26] S. Lu, Y. Zhao, K. Fang, Y. Li, P. Sun, "Establishment and experimental verification of TRNSYS model for PCM floor coupled with solar water heating system," Energy and Buildings, 140, 245-260,2017.

[27] Klein, S.A., Beckam, W.A., Mitchell, J.W., Braun, J.E., Evans B.L., Kummert J.P., et al., (2012), "TRNSYS - a transient system simulation program. Version 17", Madison: Solar Energy Laboratory, University of Wisconsin.

[28] Klein, S.A., Beckam, W.A., Mitchell, J.W., Braun, J.E., Evans B.L., Kummert J.P., et al., (2012), "Thermal Energy System Specialists, TESSLibraries. Version 17", Madison: Solar Energy Laboratory, University of Wisconsin.

[29] Phase Change Energy Solutions Brochure, Phase Change Energy Solutions [Online]. Available: http://www.phasechange.com/technology/BioPCMData-Sheet-Q29.pdf (accessed Oct. 5, 2018). 